\title{
The synthesis of condensed imidazoles I. A simple synthesis of some 1,5-diaryl-3-[2-(4,5-dimethyl-benzimidazol-2-yl)]formazans and their derivatives
}

\author{
Iveta Fryšová*, Jan Slouka, and Tomáš Gucký \\ Department of Organic Chemistry, Palacký University, Tř. Svobody 8, 77146 Olomouc, \\ Czech Republic \\ E-mail:frysova@orgchem.upol.cz
}

(received 10 May 05; accepted 21 Jun 05; published on the web 28 Jun 05)

\begin{abstract}
The condensation reaction of 1,5-diaryl-3-formazylglyoxylic acids (1) with 4,5-dimethyl-1,2diaminobenzene affords 1,5-diaryl-3-[2-(4,5-dimethyl-benzimidazol-2-yl)]-formazans (2) which have been transformed by reductive splitting into 5,6-dimethyl-benzimidazol-2-carboxamide arylhydrazones (3). Oxidative cyclization of formazanes (2) leads to the 2,3-diaryl-5-(4,5dimethyl-benzimidazol-2-yl)tetrazolium chlorides (4). The corresponding picrates (5) also have been prepared.
\end{abstract}

Keywords: Formazylglyoxylic acid, 4,5-dimethyl-o-phenylenediamine, formazan

\section{Introduction}

The condensation reaction of $\alpha$-ketocarboxylic acids with 1,2-diaminobenzene, which leads to 1,2-dihydroquinoxaline-2-ones, has been known for a long time. ${ }^{1}$ It is a general method that proceeds high yields. A large number of substituted quinoxaline derivatives ${ }^{2-4}$ has been prepared in this way. We found that the course of reaction of 1,2-diaminobenzene with 1,5-diaryl-3formazylglyoxylic acids proceeds in a different way; unexpectedly, 1,5-diaryl-3-(benzimidazol2-yl)formazans are obtained instead of quinoxaline derivatives. ${ }^{5}$ Herein we focused on the preparation of a new group of 4,5-substituted-1,5-diaryl-3-[2-benzimidazol-2-yl]formazans (2), for which oxidative cyclization and reductive splitting were expected.

\section{Results}

A modification of Bamberger's and Müller's method ${ }^{6,7}$ was employed to prepare a series of 1,5diaryl-3-formazylglyoxylic acids (1a-1f) by azocoupling of diazonium salts with sodium 
pyruvate in alkaline medium. The condensation reaction of acids (1a-1f) with 4,5-dimethyl-1,2diaminobenzene proceeded with simultaneous elimination of formic acid to afford 1,5-diaryl-3[2-(4,5-dimethyl-benzimidazol-2-yl)]formazans (2a-2f). The oxidative cyclization of formazanes (2a-2f) was performed by the action of lead(IV) tetraacetate in chloroform, and the series of 2,3diaryl-5-(2-oxo-1,2-dihydro-quinoxaline-3-yl)tetrazolium chlorides (4a-4f) was prepared. Compounds of the type $\mathbf{4}$ form their corresponding hydrates when crystallized from water. The chlorides were also transformed to the corresponding picrates (5a-5f). Reductive splitting of compounds (2a-2f) with $\mathrm{H}_{2} \mathrm{~S}$ proceeded smoothly to provide the corresponding benzimidazole-2carboxamide arylhydrazones (3a-3f).

\section{Experimental Section}

\section{1,5-Diaryl-3-(4,5-dimethyl-benzimidazol-2-yl)formazans 2a-2f. General procedure}

The mixture of formazylglyoxylic acid ${ }^{6}$ (1a-1f) $(1.00 \mathrm{mmol})$ and 4,5-dimethyl-1,2diaminobenzene $(136.2 \mathrm{mg} ; 1.00 \mathrm{mmol})$ refluxed for $5 \mathrm{~min}$ in ethanol $(6.0 \mathrm{ml})$. After cooling to $20{ }^{\circ} \mathrm{C}$, the red crystalline compound was filtered off, washed with water and dried. It was purified by recrystallization from ethanol. For further details see Tables 1-3 in the supplementary material section.

\section{4,5-Dimethylbenzimidazole-2-carboxamidarylhydrazones 3a-3f. General procedure} A solution of corresponding 1,5-diaryl-3-[2-(4,5-dimethyl-benzimidazol-2-yl)]formazane (2a-2f) $(1.00 \mathrm{mmol})$ in ethanol $(50-150 \mathrm{ml})$ was saturated with $\mathrm{H}_{2} \mathrm{~S}$. The solution was allowed to stand at room temperature in closed flask with intermittent stirring for 7 days. The reaction mixture was filtered and the filtrate was evaporated in vacuo. The solid was suspended in mixture of ethanol $(5.0 \mathrm{ml})$ and water $(3.0 \mathrm{ml})$ and allowed to stand at room temperature for $2 \mathrm{~h}$. Then it was refluxed for $10 \mathrm{~min}$ and filtered hot. The filtrate was evaporated in vacuo. The product was crystallized from ethanol-water (1:1). For further details see Tables 1-3 in the supplementary material section.

2,3-Diaryl-5-(4,5-dimethyl-benzimidazol-2-yl)tetrazolium chlorides 4a-4f. General procedure Lead(IV)tetraacetate $(0.50 \mathrm{~g} ; 1.12 \mathrm{mmol})$ was added with stirring to a solution of 1,5-diaryl-3(4,5-dimethyl-benzimidazol-2-yl)formazan (2a-2f) $(1.00 \mathrm{mmol})$ in $\mathrm{CHCl}_{3}(50-150 \mathrm{ml})$. The solution was stirred for $3 \mathrm{~h}$ at room temperature and filtered. The filtrate was evaporated in vacuo, the residue dissolved in $\mathrm{H}_{2} \mathrm{O}(10 \mathrm{ml})$ and acidified with conc. $\mathrm{HCl}$ to $\mathrm{pH} 2$. The precipitate was filtered off and the filtrate was evaporated in vacuo. The residue was dissolved in methanol (7-10 ml), filtered and evaporated again. The residue was dried in vacuum dessiccator over $\mathrm{KOH}$. Compounds (4) are hygroscopic and they were transformed into less hydroscopic picrates. For further details see tables 1-3 in the supplementary material section.

2,3-Diaryl-5-(4,5-dimethyl-benzimidazol-2-yl)tetrazolium picrates 5a-5f. General procedure A solution of sodium picrate $(251.0 \mathrm{mg} ; 1.00 \mathrm{mmol})$ in $\mathrm{H}_{2} \mathrm{O}(5 \mathrm{ml})$ was added to the stirred solution of tetrazolium salt (4a-4f) $(1 \mathrm{mmol})$ in $\mathrm{H}_{2} \mathrm{O}(1-3 \mathrm{ml})$ and stirring continued for 5 
minutes. The precipitated compound (5a-5f) was collected with suction and dried. For further details see tables 1-3 in the supplementary material section.

Melting points (Boetius) are not corrected. Electronic spectra were recorded in ethanol solution on a UV-VIS spectrometr Unicam Helios $\alpha$ in $1 \mathrm{~cm}$ cuvettes. Concentrations of the samples varied from $0.5-1.10^{-5}$ mol. $1^{-1}$. Infrared spectra were recorded as potassium bromide disks and scanned on an ATI Unicam Genesis FTIR instrument. MS spectra were recorded on ZAB-EQ (VG Analytical Ltd., England). The NMR spectra were recorded in DMSO-d 6 solutions on a Bruker AMX-300 spectrometer $(300 \mathrm{MHz})$ with TMS as internal standard. Elemental analyses were performed using an EA Elemental Analyzer (Fison Instrument).

\section{Supplementary Material}

Table 1. Characteristic data of compounds 2-5.

Table 2. ${ }^{1} \mathrm{H}-\mathrm{NMR}$ spectra of compounds $2-3$.

Table 3. IR spectra of compounds 2-3.

\section{Acknowledgements}

We are grateful to the Ministry of Education, Youth and Sport of the Czech Republic, for the grant MSM6198959216.

\section{References}

1. Hinsberg, O. Liebigs Ann. Chem. 1896, 292, 245.

2. Simpson, J. C. E. Condensed pyridazine and pyrazine rings, Weissberger, A. E. Ed.; Interscience: New York, 1953.

3. Platt, Y. T. The Quinoxalines - In Heterocyclic Compounds, R.C. Elderfield, Ed.; Wiley: New York, 1956; Vol.6, Ch. 10.

4. Morrison, D. C. J. Am. Chem. Soc. 1954, 76, 4483.

5. Wiedermannová, I.; Slouka, J.; Lemr K. Heterocyclic Commun. 2002, 8, 479.

6. Wiedermannová, I.; Slouka, J. Heterocyclic Commun. 2001, 7, 55.

7. Bamberger, E.; Müller, J. J. Prackt. Chem. 1901, 64, 199. 